\title{
Adolescentes em Situação de Prostituição: Uma Análise sobre a Exploração Sexual Comercial na Sociedade Contemporânea
}

\author{
Renata Maria Coimbra Libório \\ Universidade Estadual Paulista, Presidente Prudente
}

\begin{abstract}
Resumo
A presente pesquisa teve como objetivo principal compreender os processos que conduzem à produção da exploração sexual comercial de adolescentes na sociedade contemporânea. Realizamos uma análise da literatura da área e um estudo de campo, que contou com a participação de 14 adolescentes do sexo feminino, que se encontravam em situação de prostituição. Foram utilizados como procedimentos metodológicos: aplicação de questionáriosentrevista, realização de entrevistas abertas, observações e informações de educadoras sociais. Elaboramos o perfil sócio-demog ráfico das adolescentes e suas familias e criamos categorias temáticas expressivas dos conteúdos identificados. Constatamos que na produção do fenômeno encontram-se presentes múltiplos fatores que se entrecruzam de forma sinérgica nas trajetórias de vida das adolescentes. Ações de enfrentamento ao fenômeno requerem ações macro-estruturais e focais, nos mostrando a necessidade de repensarmos as concepções sobre os direitos das crian ças e adolescentes, vivência de sexualidade, valores culturais e sociais, que acabam por permitir a emergência e perpetuação da exploração sexual comercial de crianças e adolescentes.
\end{abstract}

Palavras-chave: Exploração sexual comercial; adolescentes; violação de direitos; pesquisa qualitativa.

Adolescents in Prostitution Situation: An Analyses of the Commercial Sexual Exploitation in the Contemporary Society

\begin{abstract}
The present research had as main objective to understand the processes that lead to the production of the commercial sexual exploitation of adolescents in the contemporary society. An analysis of the literature of the area and field study was accomplished which counted on the participation by fourteen female adolescents who were involved in the prostitution modality. We used as instruments: questionnairy-interviews, oral reports, observation and information of the social educators. The social-demographic profile of the adolescents and their families was elaborated and was created expressive thematic categories of the identified contents. We confirmed that in the production of the phenomenon there are multiple factors that intersect themselves in a synergic way in the adolescents' path life. Affronting policies require macro-structural and focal actions, besides it is necessary that we rethink the conceptions, concerning to children and adolescents rights, about the sexuality experiences, cultural and social values that end allowing the emergency and perpetuation of the commercial sexual exploitation of children and adolescents.

Keynords: Commercial sexual exploitation; adolescents; violation of rights; qualitative research.
\end{abstract}

A exploração sexual comercial de crianças e adolescentes é um fenômeno que ocorre em âmbito internacional e que tem mobilizado organizações não-governamentais, governamentais e diversos setores da sociedade no sentido de se discutirem encaminhamentos para combater essa cruel forma de violência.

Para Faleiros (2000), os anos 1990 podem ser considerados como bastante relevantes no que se refere à compreensão e enfrentamento do uso sexual de crianças e adolescentes no mercado do sexo (p. 31), devido à conscientização da sociedade quanto à extensão e complexidade desse problema. Segundo Leal (1999), após a realização da Comissão Parlamentar de Inquérito (CPI) da Prostituição Infanto-Juvenil no ano de 1993, que deu maior visibilidade a esse fenômeno em nosso país, este passou a ser concebido como exploração sexual comercial infantojuvenil e a ser tratado com base nas diretrizes do Estatuto da Criança e do Adolescente- ECA (Lei Federal 8.089/96). Todo esse processo ajudou na elucidação conceitual e atualmente podemos utilizar a seguinte definição de exploração sexual comercial, que serviu de sustentação teórica para o presente trabalho:

A exploração sexual comercial de crianças é uma violação fundamental dos direitos da criança. Esta violação abrange o abuso sexual por adultos e a remuneração em espécie ao menino ou menina e uma terceira pessoa

${ }^{1}$ Universidade Estadual Paulista Júlio de Mesquita Filho, Faculdade de Ciências e Tecnologia de Presidente Prudente, Dpto. de Educação, Rua Roberto Simonsen, 305, Centro Educacional, 19060 900, Presidente Prudente, SP, Brasil. Fone: (18)2295335 (R: 23).E-mail:liborio@prudente.unesp.br ou várias. A exploração sexual comercial de crianças constitui uma forma de coerção e violência contra crianças, que pode implicaro trabalho forçado e formas contemporâneas de escravidão. (ECPAT End Child Prostitution, Child Pornography and Trafficking of Children for Sexual Purpose, 2002: http:// www.ecpat.net/eng/CSEC/faq/faq1.asp)

O Instituto Interamericano del Niño estipulou, em 1998, que as quatro modalidades da exploração sexual comercial de crianças e adolescentes são a prostituição, o turismo sexual, a pornografia e o tráfico para fins sexuais (Leal, 1999). Ao fazer um primeiro levantamento bibliográfico sobre o tema em 1997, foi possível observar uma escassa produção de material referente ao tema em língua portuguesa. Essa mesma constatação é apontada por Rizzini (1994) e Sousa e Morais Neto (1997). Ao fazerem um levantamento sobre pesquisas realizadas sobre essa temática no Brasil, os autores destacam as dificuldades que universidades e instituições de implementação de políticas públicas voltadas para infância e adolescência tinham de estudar o fenômeno, em razão da natureza do mesmo. Apesar disso, é a partir dos anos de 1990 que observamos uma crescente visibilidade da exploração sexual comercial infanto-juvenil ocorrendo nas cidades litorâneas e nas regiões de garimpo, em razão dos relatórios preparados por organismos governamentais e não-governamentais e matérias jornalísticas. Sousa e Morais Neto (1997) indicam que a partir de 1996 há uma crescente mudança, tanto na imprensa como no meio acadêmico, que passa a estudar o tema. 
Gomes, Minayo e Fontoura (1999) constataram, em levantamento bibliográfico realizado, 12 títulos em língua portuguesa que se referiam a artigos ou capítulos de livros que abordavam especificamente o tema da prostituição infanto-juvenil, mostrando uma tímida aproximação dos pesquisadores frente ao tema. Dentre esses trabalhos devemos citar a pesquisa desenvolvida por Gomes (1996) que, ao estudar a história de vida de adolescentes em situação de exploração sexual no Rio de Janeiro, discute as categorias saúde, violência, exclusão social e prostituição.

Dentre as pesquisas desenvolvidas no Brasil, tanto por ONGs ou setores governamentais como por universidades, encontradas até $\mathrm{o}$ ano de 2000 , identificamos trabalhos ${ }^{2}$ que visavam conhecer o perfil das crianças e adolescentes envolvidas na exploração sexual. Em sua metodologia, utilizavam questionários cujos dados eram tabulados e avaliados quantitativamente, fornecendo informações percentuais sobre sua idade, etnia, escolarização, idade de início na prostituição, local de residência, informações sobre saúde reprodutiva e uso de drogas e modalidades da exploração sexual. Dentre os trabalhos encontrados, percebemos que poucas pesquisas se propunham a uma análise mais qualitativa do fenômeno, que buscasse compreender o significado que a própria adolescente explorada sexualmente dava à sua experiência. Trabalhos com esse objetivo foram desenvolvidos por Treguear e Carro (1994, 1997), na Costa Rica, e por Montgomery (1998), na Tailândia. As pesquisas mais recentes desenvolvidas no Brasil sobre a temática da exploração sexual foram desenvolvidas por Leal (2001), Sousa (2001) e Andrade (2001), sendo todas de caráter documental.

A fundamentação teórica do presente trabalho está alicerçada no referencial bibliográfico localizado, cuja leitura permitiu a definição das categorias explicativas ${ }^{3}$ que serviram para seu embasamento: a violência estrutural, social e interpessoal, aspectos psicológicos, compreendidos pelo prisma dos direitos humanos e inseridos nas discussões sobre a vivência da sexualidade durante a adolescência. A violência estrutural deve ser entendida como a violência inerente à própria forma de organização sócio-econômica e política de uma determinada sociedade. Ela pode ser caracterizada pela existência de um sistema social desigual produtor de exclusão social.

A discussão dessa categoria, assim como das contradições entre mercado e Estado, são essenciais na compreensão da violência estrutural. $O$ processo de fragilização do Estado em decorrência da reorganização das bases econômicas globais e locais, caracterizada pelas políticas neo-liberais, intensificou a desigualdade social, trazendo impactos diretos sobre a qualidade de vida da população. As transformações da economia trouxeram reflexos nas relações de governabilidade, que ficaram submetidas aos vários setores do mercado.

O contexto da violência estrutural interfere no fenômeno da exploração sexual, pois enquanto o Estado não tiver condições

\footnotetext{
${ }^{2}$ Desenvolvidos por Vasconcelos (1997), Pessoa (1995), Calil (1993) e Hazeu e Fonseca (1998).

${ }^{3}$ Embasadas mais especificamente em Leal (2001), Davidson (2001) e Muntarbhorn (2001).
}

de cumprir seu papel como promotor dos direitos da população em situação de exclusão social, permitindo o acesso às políticas públicas de qualidade em diversas áreas e o acesso a benefícios sociais, esta população estará sujeita a violações de várias naturezas. Inserida no contexto da violência estrutural e refletindo-se a partir dos valores culturais contemporâneos, a violência social - dirigida a determinados grupos sociais detentores de menor poder político, econômico e social no seio da sociedade - é outra grande protagonista nas histórias de vida de crianças e adolescentes envolvidas na exploração sexual. Inter-relacionadas, a violência estrutural e a violência social, expressa nas dimensões de raçaetnia, gênero e geração, pavimentam o caminho para a manifestação da violência interpessoal. A violência interpessoal se concretiza no interior das relações interpessoais mais diretas e pode ser de caráter intra e extra-familiar. Tal forma de violência responde mais diretamente pelo processo de vulnerabilização de mulheres, crianças e adolescentes, expondo-os a contextos destituídos de proteção às suas necessidades mais elementares.

Todo esse contexto pode ser compreendido como potencializador de um processo de desamparo social, afetivo e material que, progressivamente, pode se configurar como uma situação de risco social. Trabalhos apresentados por Engebak (1993) e Caballero (1994) referem-se aos fatores de risco aos quais estão expostas adolescentes em situação de prostituição em países da América Central e ao processo de vulnerabilização decorrente dessa vivência.

A partir dessa constatação, buscamos em Yunes e Szymanski (2001) uma explicação mais aprofundada sobre os mecanismos de risco e proteção e suas relações com vulnerabilidade. Buscávamos compreender como esses conceitos se articulavam com o fenômeno da exploração sexual. Segundo Yunes e Szymanski, é a perspectiva ecológica em psicologia, representada por Bronfenbrenner, a abordagem que melhor consegue explicar tais processos. As autoras, ao fazerem uma análise conceitual dos termos, explicam que fatores de risco referem-se a situações objetivas de vida, consideradas como estressoras do desenvolvimento infantil. Dentre elas, a literatura da área aponta a pobreza e a violência durante a infância e adolescência. O termo vulnerabilidade relaciona-se ao indivíduo e sua susceptibilidade frente às adversidades da vida; há variações na sensibilidade das crianças aos riscos enfrentados, dependendo da interrelação entre fatores subjetivos e do ambiente. Há uma relação entre risco e vulnerabilidade: essa opera somente quando o risco está presente. Ou seja, a exposição aos diversos fatores de risco pode promover o processo de vulnerabilização, impedindo que a criança ou o adolescente respondam satisfatoriamente frente às adversidades da vida. Yunes e Szymanski (2001) ressaltam que os riscos não devem ser compreendidos de forma estática, mas sim do ponto de vista dinâmico, sendo relativizados: situações que são risco para um indivíduo, podem não ser para outros indivíduos. Além disso, eventos isolados também não devem ser entendidos como risco.

Os mecanismos de proteção operam sobre o desenvolvimento, podendo ser considerados como processos que protegem as pessoas dos riscos. De acordo com Yunes e Szymanski (2001) existem três classes de mecanismos de proteção listados na literatura: a) atributos 
pessoais; b) laços afetivos na familia; c) presença de redes de apoio social. Cabe ainda citar a presença de outros elementos psicológicos que podem favorecer o encaminhamento e a manutenção de adolescentes nas redes de exploração sexual comercial: a formação das identidades pessoal e social, o processo de estigmatização, a formação de auto-imagem e auto-estima.

Autores como Gomes (1996), Treguear e Carro (1994 e 1997), Montgomery (1998), Vasconcelos (1997) e Calil (1993) abordam essas dimensões em seus trabalhos a partir de referenciais da psicologia social, em especial Goffman (1982). Acreditamos que a baixa autoestima, aliada aos sentimentos de rejeição, discriminação sentidas por algumas adolescentes, resultantes da exclusão social e vivência de violência social e interpessoal, ao serem acumulados e introjetados em sua identidade, facilitam seu envolvimento em atividades que têm caráter exploratório e violento.

O objeto de estudo desta pesquisa foi a problemática da exploração sexual comercial de adolescentes, através da modalidade prostituição. A pesquisa desenvolvida caracterizou-se por ser um trabalho de caráter teórico, com revisão de bibliografia, assim como um trabalho de campo realizado em uma cidade de médio porte, localizada no interior de São Paulo, Brasil. A referida pesquisa teve início a partir do desenvolvimento de um trabalho de supervisão realizado pela pesquisadora, nos anos de 1997 e 1998, com educadores sociais da Secretaria Municipal de Assistência Social, que trabalhavam em projetos sociais que atendiam crianças e adolescentes em situação de rua e envolvidos na exploração sexual. $\mathrm{O}$ objetivo principal da pesquisa foi compreender as características desse fenômeno, em especial os fatores que interferem na sua produção e manutenção, através das falas das adolescentes prostituídas. Os objetivos específicos foram:

a) elaborar uma caracterização sócio-econômica e familiar de um grupo de adolescentes em situação de exploração sexual comercial;

b) descrever o perfil das adolescentes em relação a: faixa etária, grupo étnico, escolaridade, conhecimentos e práticas de saúde e sexualidade e a história de seu envolvimento com a rede de exploração sexual;

c) analisar os relatos de experiências das adolescentes sobre temáticas que se relacionam com o mundo da prostituição; d) compreender a natureza da problemática estudada e as características do contexto no qual esta se insere.

\section{Método}

\section{Participantes}

Participaram da pesquisa 14 adolescentes do sexo feminino, cuja faixa etária variava de 13 a 17 anos. No período da realização da pesquisa, essas adolescentes já tinham sido encaminhadas para o Conselho Tutelar do município, que as conhecia e acompanhava. As adolescentes que participaram da pesquisa já estavam sendo exploradas sexualmente por um período que variava de 6 meses a 3 anos. $\mathrm{O}$ acesso às participantes da pesquisa se deu através do vínculo da pesquisadora junto aos educadores sociais dos projetos municipais.

\section{Instrumentos}

Foram utilizados dois instrumentos na pesquisa: questionáriosentrevista e roteiro de entrevista aberta. O questionário-entrevista foi elaborado tomando-se como base o trabalho de Pessoa (1995), Treguear e Carro (1994) e os objetivos da pesquisa, fundamentados no referencial teórico. Esse instrumento foi aplicado nas 14 participantes da pesquisa. Em 9 adolescentes o instrumento foi aplicado pela pesquisadora e 5 questionários foram aplicados por uma das educadoras sociais que recebeu orientações sobre a aplicação do mesmo. As perguntas eram apresentadas oralmente para as adolescentes, cujas respostas eram redigidas pela pesquisadora e educadora. Os 14 itens que constavam no questionário-entrevista possibilitaram o levantamento do perfil sócio-econômico das adolescentes e suas famillias, assim como seus conhecimentos e práticas de saúde e sexualidade. Com relação ao roteiro de entrevista aberta, a elaboração dos itens que o compuseram teve como referência principal os objetivos da pesquisa, a fundamentação teórica e os trabalhos realizados por Treguear e Carro (1997) e Montgomery (1998).

A entrevista aberta foi obtida com 7 adolescentes que foram selecionadas dentre aquelas que já haviam respondido o questionárioentrevista anteriormente, de acordo com os seguintes critérios:

- o prévio estabelecimento de um vínculo entre pesquisadora $\mathrm{e}$ adolescente, avaliada pelo tempo de estabelecimento dessa relação (mais de 5 meses);

- o tempo de inserção da adolescente na problemática estudada (estar envolvida na exploração sexual por mais de um ano);

- aceitação da adolescente em falar de sua condição e concordar com a gravação da entrevista aberta.

A seleção de algumas adolescentes para participarem desse procedimento foi pertinente, pois acreditávamos que para responderem a esse instrumento seria necessário que as mesmas expressassem uma representatividade, indicada pelo tempo de envolvimento na problemática estudada. Além disso, acreditávamos que o estabelecimento de uma relação prévia entre as adolescentes e pesquisadora seria um elemento facilitador para a realização das entrevistas, cujos itens exigiam uma maior introspecção das adolescentes. A aceitação da gravação da entrevista também foi um critério fundamental, em razão das questões éticas.

O roteiro de entrevista aberta continha 10 itens, apresentados a seguir:

1) a história do envolvimento da adolescente na exploração sexual comercial; 2) o significado desta atividade para ela e a consciência quanto sua inserção nessa atividade; 3) o significado atribuído ao seu corpo; 4) suas crenças pessoais ou religiosas com relação à existência de pessoas que cuidam e se preocupam com ela; 5) o relacionamento com a polícia; () as atividades de lazer ou laborais que mais gosta de se envolver ou sente que tem habilidade de desenvolver; 7) as experiências com os exploradores sexuais (clientes e aliciadores); 8) a presença de relacionamentos interpessoais significativos (recentes ou antigos); 9) a vivência de "estar na rua" e seu significado; 10) a natureza de seus desejos pessoais e suas perspectivas de futuro.

Os itens do roteiro eram apresentados um a um, obedecendo essa seqüência pré-determinada que não foi seguida rigorosamente, 
pois percebemos que o fluxo e os conteúdos da entrevista muitas vezes seguiam um curso diferente do que estava previamente estipulado. Embora havendo uma variação na direção e duração das entrevistas, tentou-se garantir que todos os temas previamente escolhidos fossem apresentados para todas adolescentes.

A obtenção das entrevistas abertas foi feita através do uso de um gravador; após as gravações as entrevistas passaram por um processo de transcrição literal.

\section{Procedimentos}

Para a coleta de dados foram realizados os seguintes procedimentos: observação, aplicação de questionários-entrevista, obtenção de entrevistas abertas e supervisão semanal com educadores. A opção pela técnica da observação se deu pela sua pertinência para concretização dos objetivos específicos da pesquisa e embasada no trabalho desenvolvido por Treguear em Carro (1994) na Costa Rica e Engebak (1993). Todas as observações foram realizadas pela pesquisadora e seus conteúdos referiam-se à ação das adolescentes enquanto permaneciam nas ruas da cidade, expostas à situação de exploração sexual, abrangendo o período de março a setembro de 1999. Durante o período em que ocorreram as observações, a pesquisadora auxiliada pela presença de uma educadora social ${ }^{4}$, comparecia, no mínimo, uma vez por semana nos pontos de prostituição. A permanência nesses locais variava de 2 a 3 horas, cujo horário de início da observação era por volta das 22 horas até aproximadamente uma hora da manhã.

Havia uma pequena variação nos horários de início e término da observação, além de serem flexíveis as atividades, os locais, as adolescentes e acontecimentos observados. Em razão da própria natureza do fenômeno, da dificuldade de prever antecipadamente as circunstâncias que seriam objeto da observação, as observações tiveram um caráter assistemático.As observações possibilitaram a obtenção de dados significativos relacionados às atitudes das adolescentes, bem como foram vivenciados acontecimentos pela pesquisadora, adolescentes e educadora, considerados relevantes para compreensão do contexto no qual se manifestava a exploração sexual na realidade estudada.

Fazendo parte do universo das observações foram obtidas informações sobre:

a) os comportamentos das adolescentes frente aos clientes; b) as atitudes das adolescentes frente às batidas policiais e frente a outras formas de violência; c) sua postura durante as discussões travadas na rua com profissionais do sexo adultas referentes briga pelo ponto; d) o comportamento das adolescentes quando estavam sob o efeito de drogas; e) relacionamento das adolescentes com seus pares e com a educadora social; e f) as ações dos exploradores sexuais (aliciadores e clientes).

\footnotetext{
${ }^{4}$ A presença dessa educadora social foi essencial na medida em que ela intermediou o contato da pesquisadora com os sujeitos da pesquisa, além de ter exercido o papel de desenvolver a confiança das adolescentes frente a figura e papel da pesquisadora. A ida para as ruas junto com um educador, que já conhecia antecipadamente os sujeitos, foi um procedimento usado também em pesquisas realizadas na América Central sobre essa temática, como pode ser visto em Treguear e Carro $(1994,1997)$, Engebak (1993) e Caballero (1994).
}

As anotações eram feitas em um diário de campo, imediatamente após o término das observações. Nos momentos de observação que se caracterizavam como bastante críticos, (como nos casos de cometimento de violência ou brigas nos pontos de prostituição e quando as adolescentes estavam sob efeito de drogas), havia uma interferência direta da educadora social. Sua intervenção se dava no sentido de intermediar os conflitos entre os envolvidos, orientar ou encaminhar as adolescentes para suas casas, através do oferecimento de passes de ônibus, por exemplo.

Vale ressaltar que, assim como a entrada no campo é uma tarefa difícil, a saída do campo é uma tarefa mais árdua ainda que traz implicações éticas. $\mathrm{O}$ afastamento da pesquisadora do campo se deu paulatinamente, havendo um espaçamento nas observações - as idas semanais passaram a ser de $10 \mathrm{em} 10$ dias e depois quinzenalmente - finalizando assim a primeira etapa de coleta de dados. As adolescentes foram informadas sobre esse afastamento. Com relação à aplicação dos questionáriosentrevista e obtenção das entrevistas abertas, cabem algumas explicações. Durante toda a fase de coleta dos dados, entre os anos de 1999 e 2000, as participantes da pesquisa contavam com o respaldo dos educadores sociais, recursos dos projetos sociais e com o acompanhamento do Conselho Tutelar do município.

Os conselheiros tutelares, no primeiro semestre de 1999, foram informados e consultados a respeito da possibilidade da pesquisadora desenvolver sua pesquisa com as adolescentes prostituídas. O projeto de pesquisa foi apresentado aos conselheiros tutelares, no qual constavam os instrumentos e procedimentos metodológicos que seriam realizados para uma apreciação e para verificar se os conselheiros autorizariam a utilização desses instrumentos com as adolescentes que eles acompanhavam. Em plenária realizada no segundo semestre de 1999, os conselheiros tutelares deram seu acordo e autorizaram a pesquisadora a entrevistar as adolescentes para a obtenção de dados para sua pesquisa junto a essa população, outorgando um termo de responsabilidade em relação aos casos que acompanhavam. Foi a partir dessa autorização que a pesquisadora apresentou a proposta da realização dos questionários-entrevista e entrevista aberta para as adolescentes.

Previamente à aplicação dos instrumentos, a pesquisadora já tinha estabelecido contato pessoal com as adolescentes via apresentação que era feita pelas educadoras sociais e pelas diversas ocasiões de observação nas ruas. Após esse período inicial de contatos com as adolescentes, a pesquisadora conversava com cada uma, explicando que estava iniciando uma pesquisa sobre o problema da exploração sexual, por estar preocupada com a situação de algumas meninas que estavam expostas à situação de prostituição. As adolescentes eram então convidadas a participar de sua pesquisa, sendo que era explicado o objetivo central desta, que era conhecer melhor a sua vida e suas experiências. Antes da aplicação dos instrumentos os mesmos eram apresentados para elas, sendo explicado os passos que seriam seguidos para sua aplicação. A aplicação dos questionários-entrevista e realização das entrevistas abertas só ocorreram após o consentimento verbal das adolescentes em participarem da pesquisa, da autorização dos conselheiros tutelares e orientações do Promotor da Vara da 
Infância e Juventude. A supervisão semanal do trabalho dos educadores sociais no projeto social do qual participavam as adolescentes ocorreu de março a novembro de 2000. Esse procedimento possibilitou um acompanhamento longitudinal das adolescentes e uma ampliação das análises a respeito de suas experiências e histórias de vidas. Nas sessões de supervisão foram obtidas informações, de maneira informal, sobre dificuldades das adolescentes para participarem dos programas oferecidos, tais como da secretaria da saúde e das atividades do projeto em si, assim como aspectos da história de vida das adolescentes e sua relação com acontecimentos atuais que poderiam estar interferindo nessa participação.

\section{Análise dos dados}

Em função da duração da fase de coleta de dados (1999 e 2000), da diversidade de informantes e instrumentos utilizados, o material coletado precisou passar por um processo de organização. De início, tabulamos dados mais objetivos coletados através dos questionáriosentrevista e elaboramos uma categorização das respostas e informações obtidas nas entrevistas abertas, observações e sessões de supervisão, da forma descrita a seguir. Os conteúdos das entrevistas abertas, após transcrição, foram lidos várias vezes separadamente e foram sendo destacados os temas que se sobressaíam nas falas das adolescentes, compondo registros individuais; em seguida, como o conjunto de registros individuais nos deu a indicação da possibilidade desse material ser trabalhado como um todo, os registros individuais passaram por uma análise transversal. Os registros individuais foram trabalhados conjuntamente, havendo um reagrupamento por temas, que teve como critérios a freqüência com que compareciam na fala das adolescentes, a complexidade e grau de relevância que demonstravam ter em razão dos objetivos da pesquisa. Esse processo foi possibilitando a construção das categorias temáticas. Um processo similar foi realizado para a construção das categorias temáticas advindas das anotações dos diários de campo da pesquisadora e das informações obtidas com os educadores sociais, através das sessões de supervisão. No final do primeiro momento da análise, existiam três conjuntos de registros, sendo um composto pelos conteúdos abordados pelo grupo de adolescentes como um todo, outro contendo os conteúdos abordados pelos educadores e outro abrangendo aqueles identificados nas observações da pesquisadora. Em seguida, analisamos os três conjuntos de registros de forma transversal, através da triangulação, que segundo Minayo (1999) deve ser concebida como:

Prova eficiente de validação. A triangulação consiste na combinação e cruzamento de múltiplos pontos de vista, através do trabalho conjunto de diversos pesquisadores, de múltiplos informantes e múltiplas técnicas de coleta de dados. A triangulação, de certa forma consagra tanto a crítica intersubjetiva como a comparação, embora os analistas dessa corrente estejam mais preocupados em mostrá-la como atividade interna que acompanha todo o processo investigativo. (1999, p. 242)

Na presente pesquisa, a elaboração final das categorias temáticas foi possível pela triangulação dos dados e pela análise transversal dos conjuntos de registro dos três diferentes grupos de informantes. As categorias temáticas foram expressivas dos conteúdos significativos presentes nas falas dos informantes, permitindo uma análise articulada dos resultados obtidos.

\section{Resultados e Discussão}

Serão apresentados alguns resultados relevantes obtidos na pesquisa referentes à caracterização sócio-econômica e familiar das adolescentes, seu perfil com relação à faixa etária, raça/etnia, escolaridade, conhecimentos e práticas de saúde e sexualidade e experiências de vida antes e durante o envolvimento na exploração sexual. Os resultados estarão sendo analisados articuladamente com as pesquisas de Calil (1993), Pessoa (1995), Treguear e Carro (1994, 1997), Vasconcelos (1997) e Leal (2001).

Com relação à faixa etária das adolescentes, na época da realização da pesquisa, houve a predominância das idades de 14 anos e entre 16 e 17 anos (11 meninas). Do ponto de vista étnico-racial, seis adolescentes eram brancas e oito afro-descendentes. Esse dado coincide com os achados de Leal (2001), que também indica uma maior número de adolescentes afro-descendentes vitimizadas sexualmente no Brasil.

No que se refere à origem sócio-econômica das adolescentes e suas famílias obtivemos o seguinte: na maioria dos casos (11 adolescentes) suas famílias residiam em regiões do município caracterizadas como de exclusão social, apresentando sérios problemas sociais ${ }^{5}$, expressando a violência estrutural. As demais adolescentes, que residiam em regiões de inclusão social, viviam em condições de privação econômica.

Com relação à escolaridade, constatamos que na época da realização da pesquisa todas as adolescentes estavam fora da escola. A maioria das adolescentes (10) apresentava um nível de escolaridade baixo, tendo concluído até a $4^{a}$ série do ensino fundamental. Essa informação coincide com os dados obtidos por Calil (1993), Pessoa (1995) e Vasconcelos (1997). Dentre os motivos apresentados pelo abandono escolar, quatro adolescentes indicaram a influência da exploração sexual diretamente nesse processo, e três adolescentes fizeram uma associação mais indireta, relacionando-o à gravidez $\mathrm{e}$ fuga de casa.

No que se refere à caracterização dos vínculos familiares, ao descreveram seus relacionamentos interpessoais com membros da familia, constatamos o predomínio de conflitos familiares desde a infância que se intensificaram na puberdade.

Cabe ressaltar que tanto os pais biológicos como outros substitutos das funções paterna ou materna são citados como cometendo violência doméstica; tios, avós e irmãos também respondem pelo cometimento dessa violência interpessoal.

Os familiares do sexo masculino cometeram um maior número de negligência e abandono, violência sexual e psicológica. Cinco adolescentes foram vitimizadas pelo abuso sexual intra-familiar, sendo

${ }^{5}$ A avaliação da exclusão social foi feita pelos seguintes indicadores: condições de infra-estrutura das moradias, material de construção, existência de rede de esgoto e água encanada, existência de serviços como coleta de lixo e transporte coletivo, caracterização da população em termos de escolaridade e renda e distribuição da mortalidade infantil. 
dois casos de atos libidinosos e três casos de estupro. Às mães e avós foi atribuído um maior número de violência física e psicológica. Esses dados coincidem com os achados de Calil (1993), Pessoa (1995) e Vasconcelos (1997). Vasconcelos encontrou nas histórias de vida de adolescentes prostituídas uma violência generalizada e cotidiana, que adquiria formas de extrema crueldade. A vivência dessa violência respondeu pelo abandono temporário ou definitivo de seus lares, que aconteceu com 11 adolescentes. $\mathrm{Na}$ época da realização da pesquisa quatro adolescentes apresentavam melhores vínculos afetivos com suas famílias, mesmo que estivessem temporariamente rompidos.

O abandono de seus lares se dava em uma idade bastante precoce, entre 10 e 11 anos. Ao saírem de casa, as opções encontradas pelas adolescentes eram vincular-se às amigas que também haviam rompido com as famílias e escola e moravam com mulheres mais velhas ou perambulavam pelas ruas da cidade, pernoitando em construções abandonadas. Dessa forma, as adolescentes passavam a conviver no mundo da rua, que na maioria dos casos foi a porta de entrada na exploração sexual.

Com relação à faixa etária na qual as adolescentes iniciaram-se na exploração sexual, nossos dados mostraram um rebaixamento nessa idade, quando comparamos nossos dados com as pesquisas de Calil (1993) e Pessoa (1995). Enquanto Calil e Pessoa observaram que esse início se dava entre os 13 e 15 anos, nossa pesquisa indicou que metade das adolescentes iniciou seu envolvimento na exploração sexual entre 10 e 12 anos e as demais entre 13 e 15 anos. Esse dado é significativo e preocupante, mostrando que esse envolvimento pode iniciar-se durante a infância (três adolescentes iniciaram-se entre $10 \mathrm{e}$ 11 anos, antes da menarca) e na passagem da infância para a adolescência (quatro delas iniciaram-se aos 12 anos).

A presença de explorador sexual, no caso dos aliciadores, foi marcante na história de nove adolescentes e eles intensificavam a vinculação das adolescentes na exploração sexual. No que se refere à caracterização da atividade da exploração sexual em si constatamos: a maioria das adolescentes (onze meninas) exercia a prostituição de rua, considerada pela literatura da área (Flowers, 1998) como a modalidade que envolve mais riscos. As adolescentes permaneciam nos pontos de prostituição por um período de tempo longo, que variava entre 4 e 6 horas, no período noturno, entre 21 e 3 horas da manhã. Sete adolescentes indicaram uma alta freqüência na realização diária de programas, que ocorriam entre 5 e 7 vezes por semana; a outra metade indicava a freqüência de 2 a 3 vezes por semana. Esses dados nos indicam um alto envolvimento na exploração sexual, demonstrando uma rotina massacrante e desumana.

Os conhecimento e práticas de saúde e sexualidade também nos mostraram informações importantes; sete adolescentes já haviam engravidado alguma vez na vida, tendo a gravidez ocorrido entre os 13 e 15 anos. Dessas, três passaram pela situação de aborto, sendo 2 abortos espontâneos (atribuídos por elas mesmas ao abuso de drogas no período inicial da gravidez) e 1 provocado. Das quatro que levaram a gravidez adiante, todas fizeram algum atendimento médico, pelo menos uma vez antes de ter o bebê.
Quando avaliamos a freqüência aos atendimentos médicos após o início da vida sexual, constatamos que até à época da realização da pesquisa, cinco adolescentes nunca tinham feito uma consulta, cinco adolescentes haviam feito de 1 a 2 consultas e quatro delas haviam feito de 3 a 5 consultas médicas. Cabe ressaltar que a freqüência aos projetos sociais favoreceu a ida das adolescentes às consultas médicas.

Podemos considerar essa freqüência baixa levando em conta as características da vida sexual das adolescentes, que é ativa e de risco, em razão da grande rotatividade de parceiros e ausência de práticas de sexo seguro. Com relação aos conhecimentos das adolescentes sobre as doenças sexualmente transmissíveis, incluindo a AIDS, obtivemos o seguinte: cinco adolescentes disseram não saber nada; as demais indicaram ter conhecimento das formas de transmissão dessas doenças, que se daria através de relações sexuais sem preservativos e contato com seringas contaminadas.

Foi possível constatar, quanto à drogadição, que as 14 adolescentes conheciam a maconha e 11 delas conheciam também a cocaína e o crack. Com relação ao uso de drogas, 13 adolescentes afirmaram ter feito uso de drogas em algum momento de sua vida; as drogas usadas em maior freqüência foram: maconha, a cocaína, o crack e o tiner. Essa alta incidência no uso de drogas entre adolescentes prostituídas também é relatada por Treguear e Carro (1994 e 1997), Vasconcelos (1997) e Calil (1993).

Foi possível observar, através da análise das categorias temáticas, que a qualidade de vida das adolescentes decaía à medida em que se intensificava sua vinculação na exploração sexual. Tal situação favorecia a emergência de novos contextos de risco tais como: possibilidades de contágio de DSTs e AIDS e de cometimento de violência fatal, agravamento no uso de drogas (que diminuía comportamentos auto-protetores e o discernimento das situações), maior número e diversidade de parceiros, intensificação da relação de dependência com os aliciadores e envolvimento com comportamentos delituosos.

Decorrente do exposto podemos observar a constante violação de direitos a que estavam expostas as adolescentes desde tenra idade que permanecia e até se intensificava a partir de seu envolvimento com a exploração sexual, caracterizando o estado de destituição de direitos e abandono social.

\section{Considerações Finais}

Pudemos constatar a abrangência e complexidade que o fenômeno da exploração sexual comercial encerra, mostrando-nos que são inaceitáveis análises simplistas e reducionistas que buscam explicações lineares ou relações causa-efeito.

Foram as violências social e estrutural que mais deixaram marcas nas vidas das adolescentes, bem como a vivência de várias manifestações de violência interpessoal. A violência sofrida dentro de casa, nas suas diferentes expressões, o rompimento (temporário ou duradouro) dos vínculos familiares significativos em uma idade precoce (por volta dos 11 anos) e a saída de seus lares, encaminhando as adolescentes para as ruas são fatores essenciais para compreender o início do processo desencadeador do envolvimento das 
adolescentes na exploração sexual. Essa realidade colocava as meninas em contato com a urgência de suprir as necessidades básicas de subsistência e as decorrentes da sociedade de consumo. Somando-se a isto, o sentimento de revolta dirigido aos seus principais agressores e o encontro com os(as) exploradores(as) sexuais compõem, associativamente, um cenário sobre o qual se produz o fenômeno da exploração sexual comercial de adolescentes na realidade pesquisada.

Vale ressaltar: a partir do acompanhamento das adolescentes nos projetos sociais constatamos que alguns fatores podem ser considerados de alto risco (por intensificarem a manutenção das adolescentes na exploração sexual dificultando seu rompimento). São eles: a) histórico de violência sexual, como o abuso sexual intra-familiar durante a infância; b) uso abusivo de drogas; e, c) presença marcante do aliciador em sua vida.

No caso das adolescentes que romperam com a exploração sexual, durante o período de tempo que freqüentaram os projetos sociais, foram observados os seguintes elementos que funcionaram como mecanismos de proteção: a) baixo envolvimento com drogas; b) recuperação dos vínculos familiares; c) participação assídua nos projetos sociais; d) formação de vínculos afetivos com os educadores sociais; e, e) inexistência de aliciadores que controlavam seus ganhos e/ou sua vida.

Observamos que as adolescentes participantes da pesquisa transitam entre duas posições que podem ser vistas como complementares: a condição de ser uma menina prostituída e vitimizada. O termo vitimizada, como nos mostra Faleiros (1998), nos remete à importância de reconhecermos que, apesar das chances de opção e liberdade de escolha estarem diminuídas nas adolescentes nessas condições, caracterizando sua condição de prostituída, não devemos anular seu poder decisório. Por mais dificuldades que possam existir na reelaboração de seus projetos de vida, em algum nível sempre haverá condição de mobilizar e expressar sua força interior, enquanto sujeitos de direitos e desejos.

Verificamos que os resultados encontrados nesta pesquisa reforçam a concepção de que a exploração sexual comercial se caracteriza por uma dimensão processual, caracterizando-se como um fenômeno que se desenrola aos poucos, tornando-se parte da história de vida de adolescentes que viveram um processo contínuo de violência, violação de direitos e vulnerabilização desde tenra idade.

Em razão da amplitude de fatores que interferem na produção e manutenção da exploração sexual comercial de adolescentes, propostas de enfrentamento do fenômeno podem ser pensadas em vários níveis. São necessárias ações mais macro-estruturais que visem à elaboração de políticas públicas mais eficientes para redução da exclusão social e fortalecimento do papel do Estado e que possibilitem modificações nos valores culturais e sociais relacionados ao gênero, classe social e etnia. Ações mais focais, visando a criminalização daqueles envolvidos em práticas violadoras e o desenvolvimento de projetos de educação afetivo-sexual em âmbito educacional também são pertinentes. Além disso, considerando que o envolvimento na exploração sexual comercial representa o elo final de um ciclo de violência, que pode se perpetuar e reproduzir de forma ininterrupta, sabemos que intervenções psicossociais junto às adolescentes já envolvidas nesta situação também é uma parte de nosso trabalho.
Baseadas em estudos e experiências no acompanhamento de crianças e adolescentes vitimizadas sexualmente, apresentaremos algumas diretrizes de intervenção inspiradas em Warburton (2001) e Franca, Teixeira e Gorgatti (2001), por considerarmos que suas reflexões estão dentre as mais importantes nessa área.

Warburton (2001), ao fazer um amplo estudo sobre diversas formas de atendimento prestados a essa população em vários países, constatou que, embora devamos avançar no sentido de avaliarmos os progressos e resultados conseguidos a partir das várias práticas existentes, houve um aumento considerável nos serviços de atendimento nessa área entre os anos de 1997 e 2001. A autora argumenta que podemos desenvolver programas de ação nas esferas da prevenção, proteção e recuperação. Esses programas podem ser norteados por diretrizes comuns: 1) promoção da conscientização dos direitos da infância; 2) adequação às diferenças da comunidade e às experiências e realidade das crianças e adolescentes atendidos; 3) manutenção da crença na capacidade de resistência dos vitimizados sexualmente; 4) promover atitudes de respeito, dignidade e aceitação; 5) promoção da participação efetiva das crianças e adolescentes (possibilitando a expressão de idéias e tomada de decisões); (6) atuação multidisciplinar, com enfoques intersetoriais e integrados; 7) promoção da resiliência entre os vitimizados sexualmente; 8) atuação baseada nos pontos fortes das crianças e adolescentes, suas famílias e comunidades; 9) incrementar a independência dos vitimizados, instrumentalizando-os através de conhecimentos e desenvolvimento de atitudes auto-protetoras; 10) fomentar os vínculos dos vitimizados com suas familias e comunidades, de forma a funcionar como redes de apoio; e, 11) favorecer uma saída real da situação de vitimização sexual, através de alternativas de geração de renda realistas e sustentáveis.

Ao abordar os programas de ação na esfera da recuperação, Warburton (2001) aponta a importância dos programas terapêuticos com crianças e adolescentes vitimizados sexualmente, ressaltando os bons resultados obtidos com essas práticas. A autora enfatiza que os resultados positivos obtidos pela intervenção terapêutica podem ocorrer numa freqüência maior quando, paralelamente, existe uma relação de apoio.

Com relação ao atendimento às adolescentes em situação de exploração sexual comercial, Franca e cols. (2001) relatam a experiência exitosa através de uma proposta de acompanhamento terapêutico, contemplando ações de natureza clínica, educativa e política. O acompanhamento terapêutico é caracterizado como uma estratégia que produz um campo de análise e intervenção ao sujeito acompanhado, permitindo o reconhecimento de seu lugar social, abrindo-o para novas formas de circulação de seu desejo no mundo. Tal estratégia ocorre no cotidiano (na casa, nos trajetos, no médico ou outros espaços sociais) das adolescentes vitimizadas e é nesse espaço que opera a escuta clínica; o acompanhante terapêutico se implica nesse cotidiano por uma relação transferencial. Nesses encontros, vai havendo a possibilidade de novas significações dos campos sociais e de suas relações com o sujeito acompanhado.

Acreditamos que o enfrentamento da exploração sexual comercial é uma tarefa árdua, que se dará a longo prazo. Mesmo sendo revestida de muitas dificuldades, limites e entraves, 
mantemos a crença nas indicações apontadas acima. Essas são formas que possibilitarão o fortalecimento dos desejos e vozes de crianças e adolescentes vitimizadas sexualmente que, embora tenham sido silenciadas, em alguns momentos, pela vida, podem se transformar em protagonistas de sua história.

\section{Referências}

Andrade, L. F. (2001). Prostituição infanto-juvenil na mídia: Estigmatização e ideologia. Tese de Doutorado não-publicada, Curso de Pós-Graduação em Psicologia Social, Pontifícia Universidade Católica de São Paulo. São Paulo, SP.

Caballero, M. E. G. (1994). Estudio sobre la prostituicion infantil em centroamerica. Guatemala: UNICEF.

Calil, M. I. (1993). Violência e prostituição na infância e adolescência. Relatório de Pesquisa não-publicada, Núcleo de Pesquisa de Extensão Comunitária, Universidade Católica de Santos. Santos, SP.

Câmara Legislativa do Distrito Federal (1993). Comissão parlamentar de inquérito destinada a apurar responsabilidades pela exploração e prostituição infanto-juvenil. Relatório final. Brasília: Câmara dos Deputados.

Davidson, J. O'C. (2001, dezembro). The sex exploiter. Trabalho apresentado no II World Congress Against the Commercial Sexual Exploitation of Children, Yokohama, Japão.

Engebak, K. (Org.)(1993). Niña: Cultura de la violencia y vulnerabilidad: Memoria del encuentro centroamericano. Guatemala: PRONICE.

Estatuto da Criança e do Adolescente (ECA) (2000). Lei Federal n 8.069, de 13-071990. Imprensa Oficial: CONDECA.

Faleiros, V. P. (1998). A violência sexual contra crianças e adolescentes e a construção de indicadores: A crítica do poder, da desigualdade e do imaginário. Em M. F. P. Leal \& M. A. César (Orgs.), Indicadores de violência intra-familiar e exploração sexual comercial de crianças e adolescentes (pp. 9-28). Brasília: CECRIA.

Faleiros, E. T. S. (2000). Repensando os conceitos de violência, abuso e exploração sexual de crianças e adolescentes. Brasilia: Thesaurus.

Flowers, B. (1998). The prostitution of women and girls. North Carolina: MacFarland.

Franca, J. C. \& Teixeira, L. C \& Gorgatti, V. (2001). Estratégias de intervenção em situação de risco, extremo risco e exploração sexual. Em L. S. Mallak \& M. G. O. M. Vasconcelos (Orgs), Compreendendo a violência sexual em uma perspectiva multidisciplinar (pp. 162-179). Carapicuíba, SP: Fundação ORSA Criança e Vida.

Goffman, E. (1982). Estigma: Notas sobre a manipulação da identidade deteriorada. Rio de Janeiro: Zahar.

Gomes, R. (1996). O corpo da rua e o corpo na rua: A prostituição infantil feminina em questão. São Paulo: Unimarco.

Gomes, R., Minayo, M. C. S. \& Fontoura, H. A. (1999). A prostituição infantil sob a ótica da sociedade e da saúde. Revista de Saúde Pública, 33,171-179.
Hazeu, M \& Fonseca, S. (1998). Exploração e violência sexual contra crianças e adolescentes no Pará. Em M. F. P. Leal \& M. A. César (Orgs.), Indicadores de violência intra-familiar e exploração sexual comercial de crianças e adolescentes (pp. 5767). Brasilia: CECRIA.

Leal, M. L. P. (1999). A exploração sexual comercial de meninos, meninas e adolescentes na América Latina e Caribe: Relatório final, Brasil. Brasilia: CECRIA.

Leal, M. L. P. (2001). A mobilização das ONGs para o enfrentamento da exploração sexual comercial de crianças e adolescentes no Brasil. Tese de Doutorado não-publicada, Curso de Pós-Graduação em Serviço Social, Pontifícia Universidade Católica de São Paulo. São Paulo, SP.

Minayo, M. C. S. (1999). O desafio do conhecimento: Pesquisa qualitativa em saúde. São Paulo: Hucitec.

Montgomery, H. (1998). Children prostitution and identity: A case study from a tourist resort in Thailand. Em K. Kempadoo \& J. Doezema (Orgs.), Global sex workers: Rights, resistance and redefinition (pp.139-150). United States: Routledge.

Muntarbhorn, V. (2001, dezembro). Report of the second world congress against commercial sexual exploitation of children. Trabalho apresentado no II World Congress Against the Commercial Sexual Exploitation of Children, Yokohama, Japão.

Pessoa, M. L. M. N. (Org.) (1995). Mulher- menina: Um estudo da exploração sexual feminina infanto-juvenil em Teresina, visibilidade do problema no Estado do Piaú. Teresina, Piauí: NUPEC/UFPI-CBIA.

Rizzini, I. (Org.) (1994). A menina e a adolescente no Brasil: Uma análise da bibliografia. Rio de Janeiro: Universitária.

Sousa, S. M. G. (2001). Prostituição infantil e juvenil: Uma análise psicossocial do discurso dos depoentes da CPI. Tese de Doutorado não-publicada, Curso de PósGraduação em Psicologia Social, Pontifícia Universidade Católica de São Paulo. São Paulo, SP.

Sousa, S. M. G. \& Morais Neto, O. L. de (1997). Abuso e exploração sexual de crianças $e$ adolescentes na região metropolitana de Goiânia. Goiânia: CERNE.

Treguear, T. L. \& Carro, C. B. (1994). Niñas prostituidas: Caso Costa Rica-Investigacion Diagnostica. San Jose, Costa Rica: UNICEF/CHILDHOPE.

Treguear, T. L. \& Carro, C. B. (1997). Niñas y adolescentes prostituidas: Silencio socialy violación de derechos. San Jose, Costa Rica: UNICEF.

Vasconcelos, A. (1997). Meninas de rua do Recife. Recife: Bagaço.

Warburton, J. (2001, dezembro). Prevención, protección y recuperación. Trabalho apresentado no II World Congress Against the Commercial Sexual Exploitation of Children, Yokohama, Japão.

Sobre a autora

Renata Maria Coimbra Libório é Doutora em Psicologia (Psicologia Escolar e Desenvolvimento Humano), pelo Instituto de Psicologia da Universidade de São Paulo. É Professora do Departamento de Educação e do Programa de Pós-Graduação em Educação da Universidade Estadual Paulista, Faculdades de Ciências e Tecnologia, Campus de Presidente Prudente, São Paulo. 